\title{
Retailer Channel Decisions of Consumer Electronics Supply Chain in a Competitive Environment
}

\author{
Lihua ZENG, Jian WANG, Yongshi HU
}

\begin{abstract}
To identify the optimal channel structure in the consumer electronics industry, the issue of channel optimisation was studied in a supply chain with one retailer and one manufacturer. This study discussed how the retailer can effectively sell products through either the online/offline retail channel or both retail channels simultaneously. Three Stackelberg game models were formulated to study these different retail channels. Then, the optimal decisions were derived in closed-form solutions for each channel. To maximize the retailer's profit, the selections of optimal channels for both retailer and manufacturer were compared, respectively, from the aspect of supply chain coordination. The analytical results indicate that the retail structure of dual-channel is the optimal choice for the retailer, which depends on the channel selection of manufacturer and the channel preference and price difference sensitivity of consumer. In addition, both retailer and manufacturer can overcome disagreement by a supply chain contract that combines the wholesale price and compensation plan. This study not only conducts the theoretical analysis for the optimal decisions of retailer channel but also provides managerial implications for the mixed-channel construction of retailers in practice.
\end{abstract}

Keywords: channel decision; consumer electronics; multi-channel supply chain; retailer

\section{INTRODUCTION}

In March 2017, RadioShack sought bankruptcy protection for the second time in just over two years. Founded in 1921, RadioShack was the second largest electronics retailer in the United States, next only to Best Buy. After first filing in 2015, RadioShack partnered with Sprint to open wireless carrier shops within 1200 RadioShack locations. Nevertheless, ingrained habits cannot be cast off overnight, and the company inevitably sought bankruptcy protection again.

The development of Internet technology and the network economy has promoted demand growth for consumer electronics year after year. Consumer electronics retail occupies an important position in the retail industry. The Consumer Technology Association predicted that the retail revenues of consumer technology industry in the United States would exceed \$377 billion in 2018, while the investment and development of the electronics industry would reach an unprecedented scale [1]. Faced with such industrial development, why did the industrial giant RadioShack seek bankruptcy protection for the second time in just over two years?

The retail industry has witnessed great changes in the past decade. The emergence of network channels and new digital channels, such as mobile and social communication media, have changed retail business modes and operations as well as the behaviours of shoppers [2]. With rapidly increasing diversified and personalized demands, and despite the high added value of consumer electronics, the technological barriers of products decline as the technological convergence becomes consistent and products are easily imitated. As consumer electronics (e.g., mobile phones and computers) are durable, consumers are reluctant to make frequent purchases within a short period of time, thereby resulting in intensifying competition in the consumer electronics industry. The competition among consumer electronics has become a comprehensive competition in the supply chain.

A growing number of consumer electronics manufacturers are beginning to create direct online channels under their own control while marketing their products through traditional retailers. This phenomenon is called manufacturer encroachment. Manufacturers exist not only as suppliers of retailers but also as direct rivals of retailers. Price competition becomes a major area where manufacturers and retailers fight for their share of the market. Furthermore, direct online channel prices are generally lower than offline retail prices, which have adverse effects on the marketing and profits of retailers [3]. Manufacturers acquire higher profits and larger markets through the direct online channels, whereas traditional retailers encounter unprecedented difficulties from the progressively smaller market and the high cost of offline retail channel construction and maintenance. For retailers, the important problem of how to construct a reasonable retail channel to get rid of their passive position in the traditional supply chain needs to be solved urgently. Therefore, this study discusses the channel decision problem of a retailer in the consumer electronics supply chain against the background of a direct online channel launched by a manufacturer.

\section{STATE OF THE ART}

Earlier studies on the multi-channel supply chain represented by Chiang focused on how a direct online channel opened by a manufacturer affects the original offline retail channel [3]. Park and Keh compared a single offline retail channel with a dual-channel and found that the dual-channel can increase the manufacturer's profits and the consumers can purchase the goods at a lower price. However, the profits of the offline retailer decreased accordingly [4]. Chiang et al. hypothesized that consumers had a higher utility of the same goods from the offline retail channel than the direct online channel and determined the threshold for the manufacturer to open a direct online channel [3]. Fruchter and Tapiero also analyzed the situation of the manufacturer that launched a direct online channel. Aside from presenting conclusions similar to those of Park and Keh [4], they discovered that charging the same price across both channels would be favourable to the manufacturer [5]. 
All of the aforementioned studies were based on the supply chain composed of one manufacturer and one retailer. Some scholars have extended this supply chain structure. Matsui investigated the optimal timing and level of wholesale and retail prices set in multi-channel supply chains involving one manufacturer and two retailers; he concluded that the manufacturer must simultaneously set its wholesale prices for products sold to separate retailers at the same time, while the retailers must sequentially set respective retail prices at different times [6]. Lan and $\mathrm{Li}$ studied a supply chain in which one manufacturer distributed products to a retailer with uncertain demands through two distributors (channels); this study demonstrated that the dual-channel system benefited the manufacturer and the retailer if the level of demand uncertainty exceeded a threshold [7]. Jafari et al. considered a dual-channel supply chain involving one manufacturer and multiple retailers and determined the equilibrium prices through the game theoretic approach [8] These studies mainly discussed competition and game between one manufacturer and two or more retailers, but only a few studies examined the important changes in the dual-channel retail activities of retailers.

As a result of the increasing use of Internet technology, the supply chain was extended from a single offline retail channel into a collaboration of multiple channels, including the direct online channel and the online retail channel, and studies on the retailer channel decisions emerged accordingly. Biyalogorsky and Naik assessed the impact of online activities on offline sales, and based on an empirical analysis, they found that the online sales did not significantly cannibalize the offline sales [9]. Karraya and Siguéb further analyzed the conditions for a traditional retailer to open an online retail channel. They found that staying out of the online market when it was still not large enough or when it was extremely large could be a better alternative for an offline retailer. Otherwise, a retailer's online expansion cannibalized offline sales but increased the retailer's overall sales [10]. In a study on an oligopoly, Bernstein et al. reported that a dual-channel was the equilibrium channel structure; however, they found that such equilibrium did not necessarily imply higher profits for the firms. In some cases, rather, the equilibrium emerged as a strategic necessity [11]. The studies mentioned on the retailer channel decisions are mainly concerned with competition and game between two retailers or different channels of the same retailer but overlooked influences of manufacturer competition on the decisions of retailers.

In the multi-channel supply chain, there is not only the vertical supply-demand relation between manufacturers and retailers but also the horizontal competitions among the different channels. Contract coordination strategy is often chosen by researchers as the solution to conflicts in a multi-channel supply chain. The common supply chain contract can generally be divided into three types: 1) Wholesale price: the price contract [12] and the quantity discount contract [13]. 2) Order quantity: the quantity flexibility contract [14] and the minimum order quantity contract [15]. 3) Benefit distribution: the compensation contract [16] and the benefit sharing contract [17]. However, since the competition between manufacturers and retailers in multiple channels leads to the double marginal effect of the supply chain, many contracts which are applied to coordinate the supply chain with the single channel cannot meet the coordination demands and the contract attributes displayed in the single channel supply chain may not be extended to the practical environment of the multi-channel supply chain [18]. Therefore, most studies revise and overlap the original contracts to coordinate the multi-channel supply chain $[19 \div 21]$.

Based on the preceding analysis, this study discusses the retailer channel decisions in the consumer electronics supply chain when the manufacturer adds a direct online channel. The study aims to solve the following problems: how the retailer sets the optimal price according to the different channel selection (an offline retail channel, an online retail channel, or a dual-channel) respectively; what the optimal channel structure of the retailer is; what the feasibility condition is; can the retailer and manufacturer's optimal channel structures reach an agreement, and if not, how they can be coordinated.

The remainder of this study is organized as follows: Section 3 constructs three models according to the different channel selection of the retailer and provides a corresponding analysis and solution. Section 4 analyzes pricing according to the model-solving results; the optimal channel structures of the retailer and manufacturer under different models are compared and the supply chain is coordinated by using the optimal profits of the retailer as the analysis standard. Section 5 presents our conclusions.

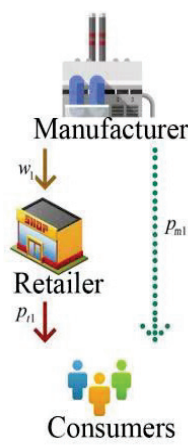

(a)

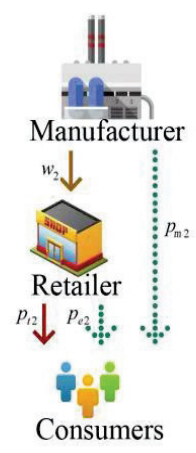

(b)

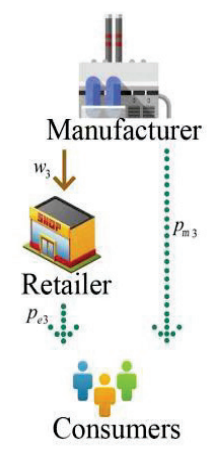

(c) $\rightarrow$ Offline retail channel

...: Online channel

Figure 1 Channel structure of supply chain: (a) Retailer's offline retail channe and manufacturer's direct online channel; (b) Retailer's dual-channel and manufacturer's direct online channel; (c) Retailer's online retail channel and manufacturer's direct online channel

\section{METHODOLOGY}

\subsection{Problem Description}

In this study, as shown in Fig. 1(a), Fig. 1(b), and Fig. 1(c), a three-level supply chain system consisting of one consumer electronics manufacturer, one retailer, and the consumers is constructed and the hypotheses are as follows: 1) The manufacturer sells products through the retailer and a direct online channel. 2) The retailer can sell products through an offline retail channel, a dual-channel or an online retail channel. 3) The manufacturer determines the wholesale price and direct online price, while the retailer determines the offline retail price and online retail price. 4) Consumers not only can acquire the basic purchase utility from the product value but can also gain the price comparison utility from different channels. The price 
comparison utility has a linear correlation with the product price difference. 5) The manufacturer and retailer pursue expected profit maximization, while the consumers pursue consumer surplus maximization.

\subsection{Notations and Assumptions}

Notations and corresponding assumptions are introduced as follows: $v$ is the consumer evaluation of the value of the unit product and $v>0 . p$ is the sale price of the unit product. $w$ is the wholesale price of the unit product. $r$ is the sensitivity coefficient of the consumer to the price difference and $0<r<1 . q$ is the quantity demanded. $\theta$ is the consumer evaluation of the offline retail channel; $\theta_{1}$ is the consumer evaluation of the online retail channel, and $\theta_{2}$ is the consumer evaluation of the direct online channel. $b$ is the change rate of marginal utility, which is generally set to 1 . The subscripts $m, r, c, t$, and $e$ represent the manufacturer (direct online channel), retailer, consumer, offline retail channel, and online retail channel, respectively. The subscripts 1,2 , and 3 indicate model 1 , model 2, and model 3, respectively. As a result of consumption upgrades, a greater number of people who buy consumer electronics are concerned about added value from multiple dimensions (e.g., material, techniques and texture) aside from the functional attributes. In particular, because the performance parameters of electronics are highly professional, these demands are difficult to meet completely in an online channel. Therefore, we hypothesize that $\theta=1,0<\theta_{1}<1$, and $0<\theta_{2}<1$.

\subsection{Model Construction}

In this study, the retailer considers three channel structures (namely, offline retail channel, dual-channel, and online retail channel) to cope with competition from the direct online channel. Based on the problem description and assumptions, the demand functions under these three channel structures of the retailer are further discussed in the following.

\section{Model 1. Retailer's Offline Retail Channel and Manufacturer's Direct Online Channel Offerings}

The utility that consumers gain from a purchase through an offline retail channel is

$$
\Pi_{c t 1}=\left[v-p_{t 1}+r\left(p_{m 1}-p_{t 1}\right)\right] q_{t 1}-\frac{b q_{t 1}^{2}}{2}
$$

The utility that consumers gain from a purchase through a direct online channel is

$\Pi_{c m 1}=\left[\theta_{2} v-p_{m 1}+r\left(p_{t 1}-p_{m 1}\right)\right] q_{m 1}-\frac{b q_{m 1}^{2}}{2}$.

As $\partial^{2} \Pi_{c t 1} / \partial q_{t 1}{ }^{2}=-b<0$ and $\partial^{2} \Pi_{c m 1} / \partial q_{m 1}{ }^{2}=-b<0$, the utilities that consumers gain from the purchase through the aforementioned two channels are the concave functions of the purchases. Let $\partial \Pi_{c t 1} / \partial q_{t 1}=0, \partial \Pi_{c m 1} / \partial q_{m 1}=0$, and $b=1$. Then, the demand functions of an offline retail channel and a direct online channel can be calculated as follows:

$$
\begin{aligned}
& q_{t 1}=v+(-1-r) p_{t 1}+r p_{m 1}, \\
& q_{m 1}=\theta_{2} v+(-1-r) p_{m 1}+r p_{t 1} .
\end{aligned}
$$

\section{Model 2. Retailer's Dual-Channel and Manufacturer's Direct Online Channel Offerings}

The utility that consumers gain from a purchase through an offline retail channel is

$$
\Pi_{c t 2}=\left[v-p_{t 2}+r\left(p_{e 2}-p_{t 2}\right)+r\left(p_{m 2}-p_{t 2}\right)\right] q_{t 2}-\frac{b q_{t 2}^{2}}{2}
$$

The utility that consumers gain from a purchase through an online retail channel is

$$
\Pi_{c e 2}=\left[\theta_{1} v-p_{e 2}+r\left(p_{t 2}-p_{e 2}\right)+r\left(p_{m 2}-p_{e 2}\right)\right] q_{e 2}-\frac{b q_{e 2}^{2}}{2}
$$

The utility that consumers gain from a purchase through a direct online channel is

$$
\Pi_{c m 2}=\left[\theta_{2} v-p_{m 2}+r\left(p_{t 2}-p_{m 2}\right)+r\left(p_{e 2}-p_{m 2}\right)\right] q_{m 2}-\frac{b q_{m 2}^{2}}{2} .
$$

As $\partial^{2} \Pi_{c t 2} / \partial q_{t 2}{ }^{2}=-b<0, \partial^{2} \Pi_{c e 2} / \partial q_{e 2}{ }^{2}=-b<0$, and $\partial^{2} \Pi_{c m 2} / \partial q_{m 2}{ }^{2}=-b<0$, the utilities that consumers gain from the purchase through all three channels are the concave functions of the purchases. Let $\partial \Pi_{c t 2} / \partial q_{t 2}=0$, $\partial \Pi_{c e 2} / \partial q_{e 2}=0, \partial \Pi_{c m 2} / \partial q_{m 2}=0$, and $b=1$. Then, the demand functions of an offline retail channel, an online retail channel, and a direct online channel can be obtained as follows:

$$
\begin{aligned}
& q_{t 2}=v+(-1-2 r) p_{t 2}+r p_{e 2}+r p_{m 2}, \\
& q_{e 2}=\theta_{1} v+(-1-2 r) p_{e 2}+r p_{t 2}+r p_{m 2}, \\
& q_{m 2}=\theta_{2} v+(-1-2 r) p_{m 2}+r p_{t 2}+r p_{e 2} .
\end{aligned}
$$

Model 3. Retailer's Online Retail Channel and Manufacturer's Direct Online Channel Offerings

The utility that consumers gain from a purchase through a direct online channel is

$$
\Pi_{c e 3}=\left[\theta_{1} v-p_{e 3}+r\left(p_{m 3}-p_{e 3}\right)\right] q_{e 3}-\frac{b q_{e 3}^{2}}{2}
$$

The utility that consumers gain from a purchase through a direct online channel is

$$
\Pi_{c m 3}=\left[\theta_{2} v-p_{m 3}+r\left(p_{e 3}-p_{m 3}\right)\right] q_{m 3}-\frac{b q_{m 3}{ }^{2}}{2}
$$

Since $\partial^{2} \Pi_{c e 3} / \partial q_{e 3}{ }^{2}=-b<0$ and $\partial^{2} \Pi_{c m 3} / \partial q_{m 3}{ }^{2}=-b<0$, the utilities that consumers gain from the purchase through 
the two aforementioned channels are the concave functions of the purchases. Let $\partial \Pi_{c e 3} / \partial q_{e 3}=0, \partial \Pi_{c m 3} / \partial q_{m 3}=0$, and $b=1$. Then, the demand functions of an online retail channel and a direct online channel can be obtained as follows:

$$
\begin{aligned}
& q_{e 3}=\theta_{1} v+(-1-r) p_{e 3}+r p_{m 3}, \\
& q_{m 3}=\theta_{2} v+(-1-r) p_{m 3}+r p_{e 3} .
\end{aligned}
$$

\subsection{Equilibrium Outcomes}

In the three models, both the manufacturer and the retailer maximize their own profits. The Stackelberg game is a common method to determine the equilibrium solution. In this study, common situations in relevant studies are applied. We hypothesize that the manufacturer is the dominator of the supply chain and the retailer is the follower. When the manufacturer is the dominator of the Stackelberg game, the two-stage Stackelberg dynamic game order is as follows: Stage 1: The manufacturer determines the wholesale price in the retail channel and the sale price in the direct online channel. Stage 2: The retailer determines the retail prices in the offline retail channel and the online retail channel.

\section{Model 1. Retailer's Offline Retail Channel and Manufacturer's Direct Online Channel Offerings}

First, the reaction function of the retailer has to be calculated by the backward induction. The profit function of the retailer in model 1 is

$\Pi_{r 1}=\left(p_{t 1}-w_{1}\right) q_{t 1}$

As $\quad \partial^{2} \Pi_{r 1} / \partial p_{t 2}{ }^{2}=-2(1+r)<0 \quad$ and let $\partial \Pi_{r 1} / \partial p_{t 1}=0$, the reaction function of the retailer can be obtained as follow:

$p_{t 1}=\frac{r p_{m 1}+v+w_{1}+r w_{1}}{2(1+r)}$.

The profit function of the manufacturer in model 1 is

$\Pi_{m 1}=w_{1} q_{t 1}+p_{m 1} q_{m 1}$.

We substitute Eq. (16) into Eq. (17). The Hesse matrix of $\Pi_{m 1}$ about $p_{m 1}$ and $w_{1}$ is $H\left(\Pi_{m 1}\right)=\left[\begin{array}{cc}\frac{-\left(2+4 r+r^{2}\right)}{1+r} & r \\ r & -1-r\end{array}\right]$. As $\frac{\partial^{2} \Pi_{m 1}}{\partial p_{m 1}^{2}}=\frac{-\left(2+4 r+r^{2}\right)}{1+r}<0$ and $\left|H\left(\Pi_{m 1}\right)\right|>0, H\left(\Pi_{m 1}\right)$ is a negative definite matrix. A unique maximum is observed about $p_{m 1}$ and $w_{1}$ in $\Pi_{m 1}$. Let $\partial \Pi_{m 1} / \partial p_{m 1}=0$ and $\partial \Pi_{m 1} / \partial w_{1}=0$. Then, the following expressions can be calculated:

$$
p_{m 1}^{*}=\frac{\left(\theta_{2}+r+\theta_{2} r\right) v}{2(1+2 r)}
$$

$$
w_{1}^{*}=\frac{\left(1+r+\theta_{2} r\right) v}{2(1+2 r)} \text {. }
$$

The following expression can be derived by substituting Eqs. (18) and (19) into Eq. (16):

$p_{t 1}^{*}=\frac{\left(3+6 r+2 r^{2}+2 \theta_{2} r(1+r)\right) v}{4(1+r)(1+2 r)}$.

The following expressions can be derived by substituting Eqs. (18)-(20) into Eqs. (15) and (17):

$$
\begin{aligned}
\Pi_{r 1}^{*} & =\frac{v^{2}}{16(1+r)}, \\
\Pi_{m 1}^{*} & =\frac{\left(1+2 \theta_{2}^{2}+\left(2+4 \theta_{2}+4 \theta_{2}^{2}\right) r+2\left(1+\theta_{2}\right)^{2} r^{2}\right) v^{2}}{8(1+r)(1+2 r)}
\end{aligned}
$$

\section{Model 2. Retailer's Dual-Channel and Manufacturer's Direct Online Channel Offerings}

First, the reaction function of the retailer has to be calculated by the backward induction. The profit function of the retailer in model 2 is

$\Pi_{r 2}=\left(p_{t 2}-w_{2}\right) q_{t 2}+\left(p_{e 2}-w_{2}\right) q_{e 2}$.

The Hesse matrix of $\Pi_{r 2}$ about $p_{t 2}$ and $p_{e 2}$ is $H\left(\Pi_{r 2}\right)=\left[\begin{array}{cc}-2(1+2 r) & 2 r \\ 2 r & -2(1+2 r)\end{array}\right]$. As $\frac{\partial^{2} \Pi_{r 2}}{\partial p_{t 2}{ }^{2}}=-2(1+2 r)<0$ and $\left|H\left(\Pi_{r 2}\right)\right|>0, H\left(\Pi_{r 2}\right)$ is a negative definite matrix. A unique maximum is observed about $p_{t 2}$ and $p_{e 2}$ in $\Pi_{r 2}$. Let $\partial \Pi_{r 2} / \partial p_{e 2}=0$ and $\partial \Pi_{r 2} / \partial p_{t 2}=0$. Then, the reaction functions of the retailer can be obtained as follows

$$
\begin{aligned}
& p_{t 2}=\frac{r(1+3 r) p_{m 2}+\left(1+2 r+\theta_{1} r\right) v+\left(1+4 r+3 r^{2}\right) w_{2}}{2+8 r+6 r^{2}}, \\
& p_{e 2}=\frac{r(1+3 r) p_{m 2}+\left(\theta_{1}+r+2 \theta_{1} r\right) v+\left(1+4 r+3 r^{2}\right) w_{2}}{2+8 r+6 r^{2}} .
\end{aligned}
$$

The profit function of the manufacturer in model 2 is

$\Pi_{m 2}=w_{2}\left(q_{t 2}+q_{e 2}\right)+p_{m 2} q_{m 2}$.

We substitute Eqs. (24) and (25) into Eq. (26). The Hesse matrix of $\Pi_{m 2}$ about $p_{m 2}$ and $w_{2}$ is $H\left(\Pi_{m 2}\right)=\left[\begin{array}{cc}\frac{-2\left(1+3 r+r^{2}\right)}{1+r} & 2 r \\ 2 r & -2(1+r)\end{array}\right]$. As $\frac{\partial^{2} \Pi_{m 2}}{\partial p_{m 2}^{2}}=\frac{-2\left(1+3 r+r^{2}\right)}{1+r}<0$ and $\left|H\left(\Pi_{m 2}\right)\right|>0, H\left(\Pi_{m 2}\right)$ is a negative definite matrix. A unique maximum is observed about $p_{m 2}$ and $w_{2}$ in $\Pi_{m 2}$. Let $\partial \Pi_{m 2} / \partial P_{m 2}=0$ and $\partial \Pi_{m 2} / \partial w_{2}=0$, and the following expressions can be calculated: 


$$
\begin{aligned}
& w_{2}^{*}=\frac{\left(1+\theta_{1}+2\left(1+\theta_{1}+\theta_{2}\right) r\right) v}{4(1+3 r)}, \\
& P_{m 2}^{*}=\frac{\left(\theta_{2}+\left(1+\theta_{1}+\theta_{2}\right) r\right) v}{2(1+3 r)} .
\end{aligned}
$$

The following expressions can be derived by substituting Eqs. (27) and (28) into Eqs. (24) and (25):

$$
\begin{aligned}
& p_{t 2}^{*}=\frac{\left(5+\theta_{1}+\left(11+7 \theta_{1}+4 \theta_{2}\right) r+4\left(1+\theta_{1}+\theta_{2}\right) r^{2}\right) v}{8(1+r)(1+3 r)}, \\
& p_{e 2}^{*}=\frac{\left(1+5 \theta_{1}+\left(7+11 \theta_{1}+4 \theta_{2}\right) r+4\left(1+\theta_{1}+\theta_{2}\right) r^{2}\right) v}{8(1+r)(1+3 r)} .
\end{aligned}
$$

The following expressions can be derived by substituting Eqs. (27)-(30) into Eqs. (23) and (26):

$$
\begin{aligned}
\Pi_{r 2}^{*}= & \frac{\left(5-6 \theta_{1}+5 \theta_{1}^{2}+\left(7-2 \theta_{1}+7 \theta_{1}^{2}\right) r\right) v^{2}}{32(1+r)(1+3 r)}, \\
\Pi_{m 2}^{*}= & \left.\left.\left.\left.\left.\frac{\left(4 \theta_{2}^{2}+\left(1+\theta_{1}\right)^{2}+\left(8 \theta_{2}^{2}+8 \theta_{2}+\theta_{1} \theta_{2}\right.\right.}{16(1+r)(1+3 r)} . \theta_{1}\right)^{2}\right)\right) r+4\left(1+\theta_{1}+\theta_{2}\right)^{2}\right) r^{2}\right) v^{2}
\end{aligned} .
$$

\section{Model 3. Retailer's Online Retail Channel and Manufacturer's Direct Online Channel Offerings}

First, the reaction function of the retailer has to be calculated by the backward induction. The profit function of the retailer in model 3 is

$\Pi_{r 3}=\left(p_{e 3}-w_{3}\right) q_{e 3}$.

As $\quad \partial^{2} \Pi_{r 3} / \partial p_{e 3}{ }^{2}=-2(1+r)<0 \quad$ and let $\partial \Pi_{r 3} / \partial p_{e 3}=0$, the reaction function of the retailer can be gained as follow:

$p_{e 3}=\frac{r p_{m 3}+\theta_{1} v+w_{3}+r w_{3}}{2(1+r)}$.

The profit function of the manufacturer in model 3 is

$$
\Pi_{m 3}=w_{3} q_{e 3}+p_{m 3} q_{m 3} .
$$

We substitute Eq. (34) into Eq. (35). The Hesse matrix of $\Pi_{m 3}$ about $p_{m 3}$ and $w_{3}$ is $H\left(\Pi_{m 3}\right)=\left[\begin{array}{cc}\frac{-\left(2+4 r+r^{2}\right)}{1+r} & r \\ r & -1-r\end{array}\right]$. As $\frac{\partial^{2} \Pi_{m 3}}{\partial p_{m 3}{ }^{2}}=\frac{-\left(2+4 r+r^{2}\right)}{1+r}<0$ and $\left|H\left(\Pi_{m 3}\right)\right|>0, \quad \Pi_{m 3}$ is a negative definite matrix, a unique maximum is observed about $p_{m 3}$ and $w_{3}$ in $\Pi_{m 3}$. Let $\partial \Pi_{m 3} / \partial p_{m 3}=0$ and $\partial \Pi_{m 3} / \partial w_{3}=0$, the following expressions can be calculated:

$$
\begin{aligned}
& p_{m 3}^{*}=\frac{\left(\theta_{2}+\theta_{1} r+\theta_{2} r\right) v}{2(1+2 r)}, \\
& w_{3}^{*}=\frac{\left(\theta_{1}+\theta_{1} r+\theta_{2} r\right) v}{2(1+2 r)} .
\end{aligned}
$$

The following expression can be derived by substituting Eqs. (36) and (37) into Eq. (34):

$p_{e 3}^{*}=\frac{\left(3 \theta_{1}+2\left(\theta_{1}+3 \theta_{2}\right) r+2\left(\theta_{1}+\theta_{2}\right) r^{2}\right) v}{4(1+r)(1+2 r)}$.

The following expressions can be derived by substituting Eqs. (36)-(38) into Eqs. (33) and (35):

$$
\begin{aligned}
\Pi_{r 3}^{*} & =\frac{\theta_{1}^{2} v^{2}}{16+16 r}, \\
\Pi_{m 3}^{*} & =\frac{\left(\theta_{1}^{2}+2 \theta_{2}^{2}+2\left(\theta_{1}+\theta_{2}\right)^{2} r+2\left(\theta_{1}+\theta_{2}\right)^{2} r^{2}\right) v^{2}}{8(1+r)(1+2 r)} .
\end{aligned}
$$

\section{RESULT ANALYSIS AND DISCUSSIONS}

In order to simplify the expressions that appear in the statement of the propositions and the proof in section 4, the following parameters are set:

$$
\begin{aligned}
& f_{1}=\frac{1-\theta_{1}+\left(9-5 \theta_{1}\right) r+2\left(7-\theta_{1}\right) r^{2}+4\left(1+\theta_{1}\right) r^{3}}{4 r(1+r)(1+2 r)} \text {, } \\
& f_{2}=\frac{1-\theta_{1}+9\left(1-\theta_{1}\right) r+2\left(9-7 \theta_{1}\right) r^{2}+4\left(2-\theta_{1}\right) r^{3}}{4(1+r) r^{2}} \text {, } \\
& f_{3}=\frac{\left(1+r+\theta_{1} r\right)(1+3 r)}{\left(1+\theta_{1}\right) r(1+2 r)^{2}} \text {, } \\
& f_{4}=\frac{\theta_{1}\left(1+4 r+3 r^{2}\right)}{\left(\theta_{1}+r+4 \theta_{1} r+4\left(1+\theta_{1}\right) r^{2}\right) r} \text {, } \\
& f_{5}=\frac{\theta_{1}(1+3 r)+\left(1+\theta_{1}\right) r^{2}}{(1+r)(1+2 r)} \text {, } \\
& f_{6}=\frac{1+\left(3-\theta_{1}\right) r}{1+r} \text {, } \\
& f_{7}=\frac{\theta_{1}+2 \theta_{1} r-r}{1+r}+\sqrt{\frac{\left(\theta_{1}^{2}(1+4 r)+2 \theta_{1}-1\right)\left(1+5 r+6 r^{2}\right)}{4 r(1+r)^{2}}}, \\
& f_{8}=\frac{1+2 r-\theta_{1} r}{1+r}+\sqrt{\frac{\left(1+5 r+6 r^{2}\right)\left(\left(1+4 r+2 \theta_{1}-\theta_{1}^{2}\right)\right.}{4 r(1+r)^{2}}}, \\
& \left(-1+2 \theta_{1}+\theta_{1}^{2}+\left(5\left(-1+2 \theta_{1}+\theta_{1}^{2}\right)+8 \theta_{1} \theta_{2}-4 \theta_{2}^{2}\right) r\right. \\
& +\left(20 \theta_{1}+10 \theta_{1}^{2}+8\left(-1+3 \theta_{1}\right) \theta_{2}-6-8 \theta_{2}^{2}\right) r^{2} \\
& f_{9}=\frac{\left.+4\left(4 \theta_{1}+4 \theta_{1}^{2}+8\left(-2+4 \theta_{1}\right) \theta_{2}-1-8 \theta_{2}^{2}\right) r^{3}\right) v^{2}}{16(1+r)(1+2 r)(1+3 r)} \\
& f_{10}=\sqrt{\frac{(1+2 r)\left(1-2 \theta_{1}+7 \theta_{1}^{2}+\left(-5+10 \theta_{1}+21 \theta_{1}^{2}\right) r+24 \theta_{1}^{2} r^{2}\right.}{8 r(1+r)^{2}}} \\
& +\frac{-r+\theta_{1}+2 \theta_{1} r}{1+r} \\
& g=\frac{\left(3-6 \theta_{1}+5 \theta_{1}^{2}+\left(1-2 \theta_{1}+7 \theta_{1}^{2}\right) r\right) v^{2}}{32\left(1+4+3 r^{2}\right)} \text {. }
\end{aligned}
$$




\subsection{Pricing Analysis}

By comparing prices set by the retailer and the manufacturer in the three models, this study finds the following:

Proposition 1: The offline retail price decreases when the offline retailer adds an online retail channel.

Proof: We assume that $p_{t 2}^{*}<p_{t 1}^{*}$, since $v>0$ and $r>0$, we have $\theta_{2}<f_{1}$. Then, Fig. 2 shows that $f_{1}>1$ if $0<\theta_{1}<1$ and $0<r<1$. As $0<\theta_{2}<1$, the assumption is obviously valid.

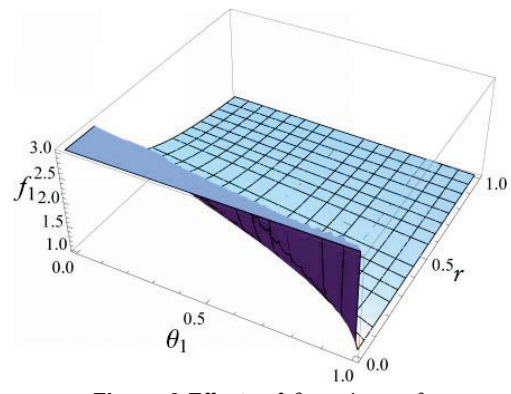

Figure 2 Effects of $\theta_{1}$ and $r$ on $f_{1}$

Proposition 2: If $\left\{\theta_{1}, \theta_{2}, r\right\} \in\left\{0<\theta_{1}<1,0<\theta_{2}<\min \left(f_{2}, 1\right), 0<r<1\right\}$, then the online retail price increases when the online retailer adds an offline channel.

Proof: We assume that $p_{e 2}^{*}>p_{e 3}^{*}$, since $v>0$ and $r>0$, we have $\theta_{2}<f_{2}$. Then, Fig. 3 shows that $f_{2}>0$ if $0<\theta_{1}<1$ and $0<r<1$. If $0<f_{2}<1$, then the assumption is valid if and only if $0<\theta_{2}<f_{2}$. If $f_{2}>1$, since $0<\theta_{2}<1$, the assumption is obviously valid. To summarize, if $\left\{\theta_{1}, \theta_{2}, r\right\} \in\left\{0<\theta_{1}<1,0<\theta_{2}<\min \left(f_{2}, 1\right), 0<r<1\right\}$, then we have $p_{e 2}^{*}>p_{e 3}^{*}$.

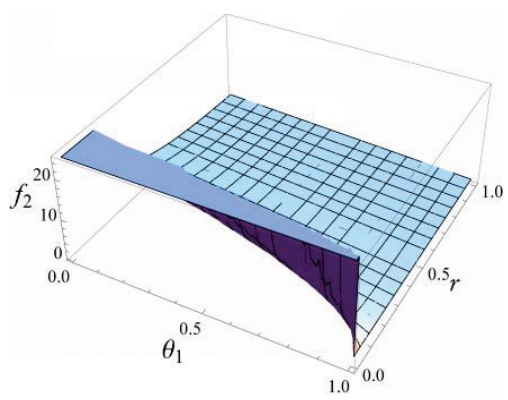

Figure 3 Effects of $\theta_{1}$ and $r$ on $f_{2}$

Proposition 1 reflects that the consumers can purchase the products from the offline retail channel at a lower price when the offline retailer adds an online retail channel. But proposition 2 shows that if the system parameters are in the threshold range, then the consumers have to purchase the products from the online retail channel at a higher price when the online retailer adds an offline retail channel. In the dual-channel retail structure, retailer reduces the offline retail price but increases the online retail price. This is done not only to prevent the loss of consumers in the offline retail channel because of competition with the manufacturer but also to restrict the large-scale transfer of the consumers from the offline retail channel to the online retail channel.

Proposition 3: If $\left\{\theta_{1}, \theta_{2}, r\right\} \in\left\{0<\theta_{1}<1,0<\theta_{2}<\min \left(f_{3}, 1\right), 0<r<1\right\}$, then the wholesale price decreases when the offline retailer adds an online retail channel.

Proof: We assume that $w_{2}^{*}<w_{1}^{*}$, since $v>0$ and $r>0$, we have $\theta_{2}<f_{3}$. Then, Fig. 4 shows that $f_{3}>0$ if $0<\theta_{1}<1$ and $0<r<1$. If $0<f_{3}<1$, then the assumption is valid if and only if $0<\theta_{2}<f_{3}$. If $f_{3}>1$, as $0<\theta_{2}<1$, the assumption is obviously valid. To summarize, if $\left\{\theta_{1}, \theta_{2}, r\right\} \in\left\{0<\theta_{1}<1,0<\theta_{2}<\min \left(f_{3}, 1\right), 0<r<1\right\}$, then we have $w_{2}^{*}<w_{1}^{*}$.

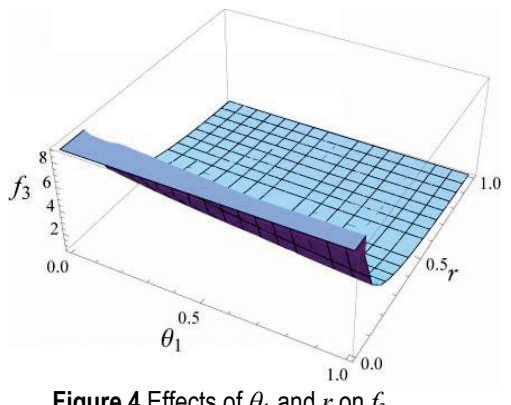

Figure 4 Effects of $\theta_{1}$ and $r$ on $f_{3}$

Proposition 4: If $\left\{\theta_{1}, \theta_{2}, r\right\} \in\left\{0<\theta_{1}<1,0<\theta_{2}<\min \left(f_{4}, 1\right), 0<r<1\right\}$, then the wholesale price decreases when the online retailer adds an offline retail channel.

Proof: We assume that $w_{2}^{*}<w_{3}^{*}$, since $v>0$ and $r>0$, we have $\theta_{2}<f_{4}$. Then, Fig. 5 shows that $f_{4}>0$ if $0<\theta_{1}<1$ and $0<r<1$. If $0<f_{4}<1$, then the assumption is valid if and only if $0<\theta_{2}<f_{4}$. If $f_{4}>1$, as $0<\theta_{2}<1$, the assumption is obviously valid. To summarize, if $\left\{\theta_{1}, \theta_{2}, r\right\} \in\left\{0<\theta_{1}<1,0<\theta_{2}<\min \left(f_{4}, 1\right), 0<r<1\right\}$, then we have $w_{2}^{*}<w_{3}^{*}$.

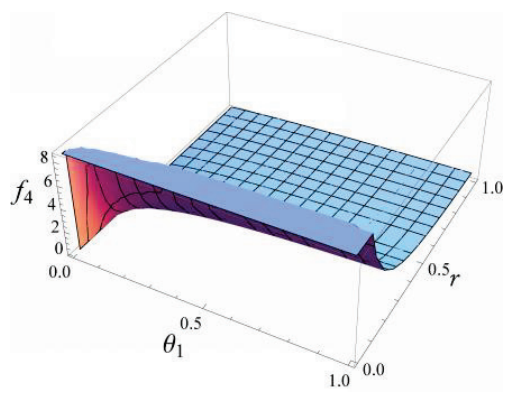

Figure 5 Effects of $\theta_{1}$ and $r$ on $f_{4}$

Propositions 3 and 4 demonstrate that if the system parameters are in the threshold range, then the wholesale price decreases when the retailer adopts a dual-channel retail structure. The manufacturer can increase profits by increasing the wholesale price when the retailer adopts a single retail channel. However, with a dual-channel retail 
structure, on the one hand, the retailer weakens the manufacturer's competitive edge. On the other hand, the growing market of the retailer brings the manufacturer additional profit space. In this case, the retailer shall adopt the follower strategy and make strategic responses to wholesale price changes set by the manufacturer in time.

Proposition 5: If $\left\{\theta_{1}, \theta_{2}, r\right\} \in\left\{0<\theta_{1}<1,0<\theta_{2}<\min \left(f_{5}, 1\right), 0<r<1\right\}$, then the direct online price decreases when the offline retailer adds an online retail channel.

Proof: We assume that $p_{m 2}^{*}<p_{m 1}^{*}$, since $v>0$ and $r>0$, we have $\theta_{2}<f_{5}$. Then, Fig. 6 shows that $f_{5}>0$ if $0<\theta_{1}<1$ and $0<r<1$. If $0<f_{5}<1$, then the assumption is valid if and only if $0<\theta_{2}<f_{5}$. If $f_{5}>1$, as $0<\theta_{2}<1$, then the assumption is obviously valid. To summarize, if $\left\{\theta_{1}, \theta_{2}, r\right\} \in\left\{0<\theta_{1}<1,0<\theta_{2}<\min \left(f_{5}, 1\right), 0<r<1\right\}$, then we have $p_{m 2}^{*}<p_{m 1}^{*}$.

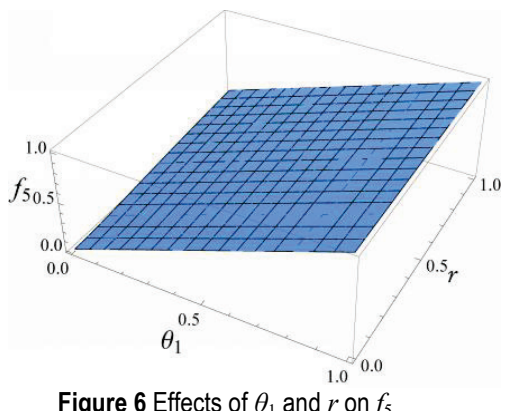

Proposition 6: The direct online price decreases when the online retailer adds the offline retail channel.

Proof: We assume that $p_{m 2}^{*}>p_{m 3}^{*}$, since $v>0$ and $r>0$, we have $\theta_{2}<f_{6}$. Then, Fig. 7 shows that $f_{6}>1$ if $0<\theta_{1}<1$ and $0<r<1$. As $0<\theta_{2}<1$, the assumption is obviously valid.

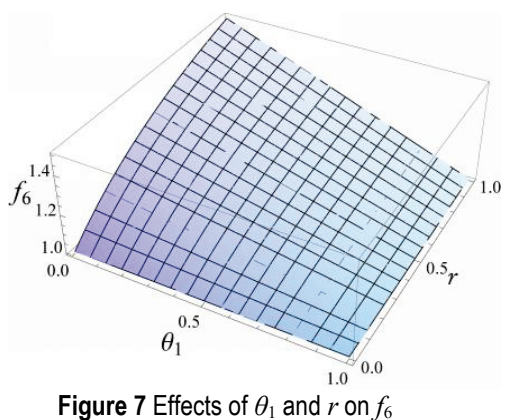

Propositions 5 and 6 demonstrate the consumers can purchase the products from the direct online channel of the manufacturer at a lower price when the retailer adopts a dual-channel retail structure. Faced with a dual-channel of retailer, the competitiveness of the manufacturer's direct online channel weakens due to the retailer's advantages in geological position and online-offline cooperation. The manufacturer improves the competitive edge of its direct online channel by reducing the direct online price, which further intensifies the price competition with the retailer.
For products with complicated attributes such as consumer electronics, the retailers can avoid pure price competition through the differential strategy and meet the consumer preference of the specific market by seeking differentiation positively, thereby increasing their own profits.

\subsection{Profit Analysis}

Proposition 7: The offline retailer gains more profits when it adds an online retail channel.

Proof: We assume that $\Pi_{r 2}^{*}>\Pi_{r 1}^{*}$, since $v>0$ and $r>0$, we have $3-6 \theta_{1}+5 \theta_{1}^{2}+\left(1-2 \theta_{1}+7 \theta_{1}^{2}\right) r>0$. Then, since $0<\theta_{1}<1$, the assumption is obviously valid.

Proposition 7 reflects the offline retailers in the consumer electronics supply chain should adjust their management strategy and open an online retail channel to adapt to the environment. As young people are the main consumers of electronics, the marketing channel should be expanded by using network resources. Except for large platforms, maximizing the advertising and word-of-mouth effects of many social communication platforms, such as WeChat and Facebook, is advantageous. Product information should be released on time based on the different platforms, marketing activities conforming to hobbies of the younger population should be held, and the product popularity should be expanded. Furthermore, efforts should be made to combine marketing and services, provide high-quality marketing services, optimize product experience of the offline retail channel comprehensively, and meet the multi-aspect demands of the consumers.

Proposition 8: The online retailer gains more profits when it adds an offline channel.

Proof: We assume that $\Pi_{r 1}^{*}>\Pi_{r 3}^{*}$, we have $\frac{v^{2}}{16(1+r)}>\frac{\theta_{1}^{2} v^{2}}{16(1+r)}$. Since $0<\theta_{1}<1, \quad \Pi_{r 1}^{*}>\Pi_{r 3}^{*}$ obviously holds. Moreover, we have $\Pi_{r 2}^{*}>\Pi_{r 1}^{*}$ from Proposition 7. To summarize, we have $\Pi_{r 2}^{*}>\Pi_{r 3}^{*}$.

Proposition 8 reveals that the online retail channel cannot replace the offline retail channel completely. Although the online retail channel possesses advantages in retail price and is conducive to increase the perceived product value of consumers sensitive to the price difference, meeting the diversified service demands of the consumers is difficult. As the buyer and the seller are not trading faceto-face in the online retail channel, consumers experience difficulty in developing a sense of trust. Particularly, making changes or refunds using after-sale services is a troublesome task that decreases the consumer's preference for the online retail channel and further decreases the perceived product value.

According to Propositions 7 and 8, the dual-channel retail structure is the optimal strategy of the retailer. On the one hand, a dual-channel retail structure helps the retailer achieve larger market coverage and reduce dependence on the offline retail channel. On the other hand, the brand 
loyalty formed by the offline retail channel helps the online retail channel to win higher trust from consumers and enhances the retailer's market competitiveness. The larger market coverage and the stronger market competitiveness are the profit growth sources after the retailer chooses the dual-channel retail structure and the fundamental driving force for the retailer to break the single channel structure.

Proposition 9: If

$\left\{\theta_{1}, \theta_{2}, r\right\} \in\left\{\frac{-1+\sqrt{2(1+2 r)}}{1+4 r}<\theta_{1}<1,0<\theta_{2}<\min \left(f_{7}, 1\right), 0<r<1\right\}$, then the manufacturer achieves the highest profits when it adopts a dual-channel retail structure.

Proof: We assume that $\Pi_{m 2}^{*}>\Pi_{m 1}^{*}$, since $v>0$ and $r>0$, we have $\frac{-1+\sqrt{2(1+2 r)}}{1+4 r}<\theta_{1}<1$ and $0<\theta_{2}<\min \left(f_{7}, 1\right)$. We assume that $\Pi_{m 1}^{*}>\Pi_{m 3}^{*}$, and we have $2\left(1+2 \theta_{2}-\theta_{1}^{2}-2 \theta_{1} \theta_{2}\right) r^{2}+\left(2+4 \theta_{2}+4 \theta_{2}^{2}-2 \theta_{1}^{2}-4 \theta_{1} \theta_{2}\right) r+1-\theta_{1}^{2}>0$. As $0<\theta_{1}<1$ and $0<\theta_{2}<1$, it is clear that $\Delta=-4\left(-1+\theta_{1}\right)^{2}\left(1+2 \theta_{1}+\theta_{1}^{2}-4 \theta_{2}^{2}\right)<0$ and the quadratic coefficient of inequality $2\left(1+2 \theta_{2}-\theta_{1}^{2}-2 \theta_{1} \theta_{2}\right)>0$. Hence, we have $\Pi_{m 1}^{*}>\Pi_{m 3}^{*}$. To summarize, Proposition 9 holds

\section{Proposition 10: If}

$\left\{\theta_{1}, \theta_{2}, r\right\} \in\left\{0<\theta_{1}<\frac{-1+\sqrt{2(1+2 r)}}{1+4 r}, f_{7}\left(\theta_{1}, r\right)<\theta_{2}<\min \left(f_{8}, 1\right), 0<r<1\right\}$, then the manufacturer achieves the highest profits when it adopts an offline retail structure.

Proof: Assuming that $\Pi_{m 2}^{*}>\Pi_{m 3}^{*}$, we have $0<\theta_{1}<1$ and $0<\theta_{2}<\min \left(f_{8}, 1\right)$. Then, we have $\Pi_{m 1}^{*}>\Pi_{m 2}^{*}$ if $0<\theta_{1}<\frac{-1+\sqrt{2(1+2 r)}}{1+4 r}$ and $f_{7}\left(\theta_{1}, r\right)<\theta_{2}<1$ from the proof of Proposition 9. Since $0<r<1$, we have $0<\frac{-1+\sqrt{2(1+2 r)}}{1+4 r}<1$.To summarize, Proposition 10 holds.

Propositions 9 and 10 reflect that in the supply chain dominated by the manufacturer, the manufacturer's optimal retail channel is influenced by the channel preference and the price difference sensitivity of consumers when the manufacturer opens a direct online channel. By comparing these propositions with Propositions 7 and 8, we find that the optimal channel selection of the retailer is not completely consistent with that of the manufacturer. In the supply chain dominated by the manufacturer, the manufacturer is the maker of the transaction contract. Therefore, the retailer shall strengthen its power to compete against the manufacturer, increase bargaining power, and realize optimal channel selection through contract negotiation.

\subsection{Supply Chain Coordination}

Based on the profit analysis, the optimal channels of the retailer and the manufacturer are not completely consistent. In this case, a conflict occurs between the retailer and the manufacturer in terms of the optimal channel. This study aims to coordinate the supply chain by a combined contract of the wholesale price and the compensation and checks whether the retailer and the manufacturer can reach an agreement on the channel selection through coordination. We suppose that the coordination strategy is feasible as long as two conditions exist: 1) The retailer's profits from the dual-channel retail structure after the coordination is still higher than that from the single offline retail channel before the coordination. 2) The manufacturer's profits from the dual-channel retail structure after the coordination is higher than that from the single offline retail channel before the coordination.

Proposition 11: In the supply chain dominated by the manufacturer, the retailer and the manufacturer can handle the inconsistency of optimal channel selections between them, realize the supply chain coordination, and create win-win situations through the combined contract of the wholesale price and the compensation.

Proof: To distinguish from the $(w)$ contract in the previous text, the wholesale contract is represented by $\left(w^{\prime}\right)$ in this section. Moreover, profits, demand and prices are distinguished by '. We suppose the manufacturer provides the contract $\left(w^{\prime}, F\right)$. The retailer collects a fixed cost $(F)$ from the profits to compensate for the manufacturer. Same as the game order in section 3.4, the decision problem of the retailer under this contract is

$\left\{\begin{array}{l}\max \left(\Pi_{r 2}{ }^{\prime}\right)=\left(p_{t 2}{ }^{\prime}-w_{2}{ }^{\prime}\right) q_{t 2}{ }^{\prime}+\left(p_{e 2}{ }^{\prime}-w_{e 2}{ }^{\prime}\right) q_{e 2}{ }^{\prime}-F \\ \Pi_{r 2}{ }^{\prime *}>\Pi_{r 1}{ }^{*}\end{array}\right.$

The decision problem of the manufacturer is

$\left\{\begin{array}{l}\underset{p_{m 2} 2^{\prime}, w_{2}{ }^{\prime}}{\max \left(\Pi_{2}\right)=w_{2}{ }^{\prime}\left(q_{t 2}{ }^{\prime}+q_{e 2}{ }^{\prime}\right)+p_{m 2}{ }^{\prime} q_{m 2}{ }^{\prime}+F} \\ \Pi_{m 2}{ }^{*}>\Pi_{m 1}^{*}\end{array}\right.$

Assuming that $\Pi_{r 2}{ }^{{ }^{*}}>\Pi_{r 1}{ }^{*}$, we have $F<g$.

Assuming that $\Pi_{m 2}{ }^{{ }^{*}}>\Pi_{m 1}{ }^{*}$, we have $F>f_{9}$.

Therefore, if $g>f_{9}$, there exists $F$ such that $f_{9}<F<g$. Then we solve $g-f_{9}>0$ and we have

$$
\begin{aligned}
& \left\{\theta_{1}, \theta_{2}, r\right\} \in\left\{0<\theta_{1}<1,0<\theta_{2}<\min \left(f_{10}, 1\right), 0<r<\frac{1}{5}\right\} \cup \\
& \left\{\frac{1-5 r+\sqrt{2\left(-3+2 r+53 r^{2}+60 r^{3}\right)}}{7+21 r+24 r^{2}}<\theta_{1}<1,0<\theta_{2}<\min \left(f_{10}, 1\right), \frac{1}{5}<r<1\right\}
\end{aligned}
$$

If $\left\{\theta_{1}, \theta_{2}, r\right\}$ is subject to Eq.(54), then a number $F$ exists to realize the supply chain c oordination. Whether $\left\{\theta_{1}, \theta_{2}, r\right\}$ is subject to Eq. (54) when the manufacturer adopts an offline retail structure cannot be judged from the calculation directly due to the complicated results. A case study is conducted in the following. 
Let $f_{11}=\frac{-1+\sqrt{2(1+2 r)}}{1+4 r}$. In Fig. 8 , there exists $\theta_{1} \in\left\{0<\theta_{1}<f_{11}\right\}$ when $0<r<0.2$.

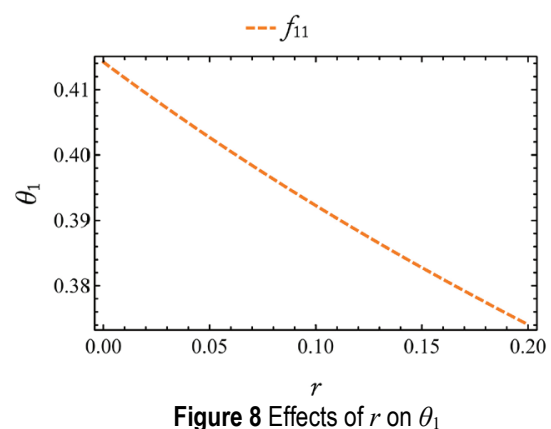

Let $\theta_{1}=0.4$. We can derive from Fig. 9 that there exist $\theta_{2} \in\left\{f_{7}<\theta_{2}<\min \left(f_{8}, 1\right) \cap 0<\theta_{2}<\min \left(f_{10}, 1\right) \mid \theta_{1}=0.4,0<r<0.2\right\}$. Therefore, when the manufacturer's optimal channel selection is the offline retail channel, at least one $F$ makes the $\left(w^{\prime}, F\right)$ contract effective, thereby making the channel selections of the retailer and the manufacturer consistent and realizing the supply chain coordination.

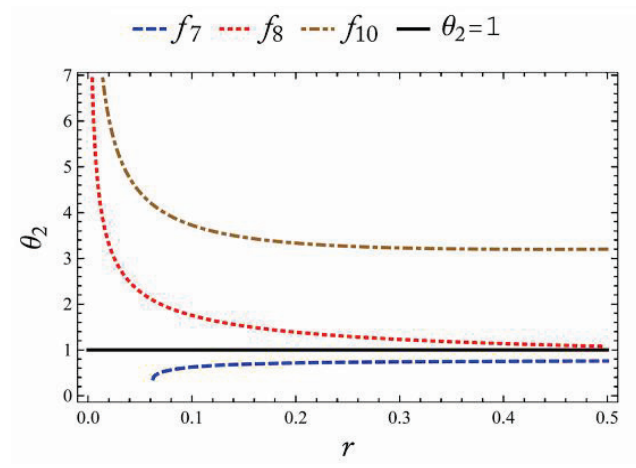

Figure 9 Effects of $r$ on $\theta_{2}$

Proposition 11 demonstrates that the retailer adopting the dual-channel retail structure shall provide appropriate compensation for the competition of the manufacturer's direct online channel. Although the retailer profit decreases because of the compensation to the manufacturer, it is still higher than when the single retail channel is selected. On the contrary, the dual-channel retail structure is the optimal strategy of the manufacturer after gaining the compensation. This result is a win-win situation. Therefore, the $\left(w^{\prime}, F\right)$ contract coordinates the channel conflict better than the $(w)$ contract. Under this circumstance, the retailer's compensation cost to reach an agreement on the channel decision between the manufacturer and the retailer is a feasible interval in which the upper and lower limits are the functions of the system parameters. In reality, the compensation cost of the retailer $(F)$ is related to the bargaining capacities of the two parties and the dualchannel retailer should take the initiative to increase bargaining capacities through an online-offline coordination.

\section{CONCLUSIONS}

To determine the channel structure for the retailer in the consumer electronics supply chain to increase market profits and realize supply chain coordination to the maximum extent in the competitive environment, a consumer utility function was constructed and a Stackelberg game model was established to analyze the various channel decisions of the retailer in a supply chain composed of one retailer and one manufacturer who opened the direct online channel. The following conclusions could be drawn:

(1) The offline retail price decreases when the offline retailer opens an online retail channel. When the online retailer opens an offline retail channel, the online retail price increases as the system parameters are in the threshold range.

(2) When the retailer uses the dual-channel retail structure, the wholesale price of the manufacturer decreases as the system parameters are in the threshold range.

(3) The optimal channel selection of the retailer is the dual-channel retail structure. Whether the optimal channel selection of the retailer is consistent with that of the manufacturer is related to the system parameters.

(4) When the optimal channel selection of the retailer is inconsistent with that of the manufacturer, the supply chain coordination can be realized through the combined contract of the wholesale price and the compensation.

Compared with existing studies on multi-channel supply chains, this study considered the dual-channel retail structure and competitive environment of the direct online channel simultaneously, which accurately described the practical situation of the consumer electronics supply chain The research conclusions provide theoretical proof for the channel decisions of the retailer in the consumer electronics supply chain and serve as practical reference for retailers on how to construct the mixed-channel structure. The main limitation of this study is that it described the perceived value difference of consumers in the different channels by a single parameter. However, the perceived value difference of consumers in the different channels of consumer electronics originates from multiple factors. These factors can be explored in future research.

\section{Acknowledgements}

This work was supported by the National Social Science Foundation of China (18BGL018).

\section{REFERENCES}

[1] CTA (Consumer Technology Association). (2018, July). U.S. Consumer Technology Sales and Forecasts (20142019). Retrieved from https://www.cta.tech/ResearchStandards/Reports-Studies/Studies/2018/U-S-ConsumerTechnology-Sales-Forecasts-2013-20.aspx

[2] Verhoef, P. C., Kannan, P. K., \& Inman, J. J. (2015). From multi-channel retailing to omni-channel retailing: Introduction to the special issue on multi-channel retailing. Journal of Retailing, 91(2), 174-181. https://doi.org/10.1016/j.jretai.2015.02.005

[3] Chiang, W. K., Chhajed, D., \& Hess, J. D. (2003). Direct marketing, indirect profits: A strategic analysis of dual- 
channel supply-chain design. Management Science, 49(1), 120. https://doi.org/10.1287/mnsc.49.1.1.12749

[4] Park, S. Y. \& Keh, H. T. (2003). Modelling hybrid distribution channels: A game-theoretic analysis. Journal of Retailing \& Consumer Services, 10(3), 155-167. https://doi.org/10.1016/S0969-6989(03)00007-9

[5] Fruchter, G. E. \& Tapiero, C. (2005). Dynamic online and offline channel pricing for heterogeneous customers in virtual acceptance. International Game Theory Review, 7(2), 137-150. https://doi.org/10.1142/S0219198905000454

[6] Matsui, K. (2018). When and what wholesale and retail prices should be set in multi-channel supply chains? European Journal of Operational Research, 267(2), 540-554. https://doi.org/10.1016/j.ejor.2017.11.069

[7] Lan, Y., Li, Y., \& Papier, F. (2018). Competition and coordination in a three-tier supply chain with differentiated channels. European Journal of Operational Research, 269(3), 870-882. https://doi.org/10.1016/j.ejor.2018.02.032

[8] Jafari, H., Hejazi, S. R., \& Rasti-Barzoki, M. (2017). Pricing decisions in dual-channel supply chain with one manufacturer and multiple retailers: A game-theoretic approach. RAIRO-Operations Research, 51(4), 1269-1287. https://doi.org/10.1051/ro/2017003

[9] Biyalogorsky, E. \& Naik, P. (2003). Clicks and mortar: The effect of on-line activities on off-line sales. Marketing Letters, 14(1), 21-32. https://doi.org/10.1023/A:1022854017292

[10] Karraya, S. \& Siguéb, S. P. (2018). Offline retailers expanding online to compete with manufacturers: Strategies and channel power. Industrial Marketing Management, 71(5), 203-214. https://doi.org/10.1016/j.indmarman.2018.01.004

[11] Bernstein, F., Song, J. S., \& Zheng, X. N. (2008). "Bricksand-mortar" vs "clicks-and-mortar": An equilibrium analysis. European Journal of Operational Research, 187(3), 671-690. https://doi.org/10.1016/j.ejor.2006.04.047

[12] Devlin, A. G., Elmaghraby, W., \& Hamilton, R. W. (2018). Why do suppliers choose wholesale price contracts? End-ofseason payments disincentivize retailer marketing effort. Journal of the Academy of Marketing Science, 46(2), 212233. https://doi.org/10.1007/s11747-017-0550-9

[13] Mohammadivojdan, R., \& Geunes, J. (2018). The newsvendor problem with capacitated suppliers and quantity discounts. European Journal of Operational Research, 271(1), 109-119. https://doi.org/10.1016/j.ejor.2018.05.015

[14] Chung, W., Tallur, S., \& Narasimhan R. (2014). Quantity flexibility contract in the presence of discount incentive. Decision Sciences, 45(1), 49-79. https://doi.org/10.1111/deci.12058

[15] Li, S., Murat, A., \& Huang, W. (2009). Selection of contract suppliers under price and demand uncertainty in a dynamic market. European Journal of Operational Research, 198(3), 830-847. https://doi.org/10.1016/j.ejor.2008.09.038

[16] Chow, P. S., Wang, Y., Choi, T. M., \& Shen, B. (2015). An experimental study on the effects of minimum profit share on supply chains with markdown contract: Risk and profit analysis. Omega, 57, 85-97. https://doi.org/10.1016/j.omega.2013.11.007

[17] Yao, Z., Leung, S. C. H., \& Lai, K. K. (2008). Manufacturer's revenue-sharing contract and retail competition. European Journal of Operational Research, 186(2), 637-651. https://doi.org/10.1016/j.ejor.2007.01.049

[18] Cachon, G. P. \& Kök, A. G. (2010). Competing manufacturers in a retail supply chain: on contractual form and coordination. Management Science, 56(3), 571-589. https://doi.org/10.1287/mnsc.1090.1122

[19] Li, C. F. \& Feng, L. P. (2014). Stackelberg gamecoordination analysis of multi-channel supply chain with stochastic demands. Computer Integrated Manufacturing Systems, 20(9), 2313-2319. https://doi.org/10.13196/j.cims.2014.09.028
[20] David, A. \& Adida, E. (2015). Competition and coordination in a two-channel supply chain. Production and Operations Management, 24(8), 1358-1370. https://doi.org/10.1111/poms.12327

[21] Zhang, P., He, Y., \& Shi, C. (2017). Transshipment and coordination in a two-echelon supply chain. RAIROOperation Research, 51(3), 729-747. https://doi.org/10.1051/ro/2016052

\section{Contact information:}

Lihua ZENG, PhD Candidates

School of Economic and Management, Fuzhou University, 2 Xueyuan Road, Higher Education Mega Center,

Fuzhou, Fujian Province, China

E-mail:5655078@qq.com

Jian WANG, Professor, PhD

(Corresponding author)

School of Economic and Management, Fuzhou University,

2 Xueyuan Road, Higher Education Mega Center,

Fuzhou, Fujian Province, China

E-mail: missingswallow@163.com

Yongshi HU, Associate Professor, PhD

School of Transportation, Fujian University of Technology,

33 Xuefu South Road, Higher Education Mega Center,

Fuzhou, Fujian Province, China

E-mail: hys820728@163.com 